\title{
Factorial Validation of an Academic Environment Scale for Undergraduate Education Students in Jos, Nigeria
}

\author{
Professor Christiana Amaechi Ugodulunwa \\ Department of Educational Foundations, Faculty of Education, University of Jos, Nigeria \\ Corresponding Author Email: ugodulunwac@gmail.com; ugochr@unijos.edu.ng
}

Mr Amos Abiodun Adeyemo

Omega High School, Jos, Nigeria

Email:amosabbey09@yahoo.com

Doi:10.5901/mjss.2016.v7n6p205

\section{Abstract}

\begin{abstract}
This study developed and validated an academic environment assessment scale for undergraduate education students in the Faculty of Education of a University in Nigeria. Dearth of reliable academic environment assessment scale and persistent poor performance of students over the years in Research Methods and Statistics courses prompted the study. A sample of 310 students was drawn from a population of 790 final year undergraduate education students in 2013/2014 academic session, using a stratified sampling technique. A 43-item Academic Environment Scale (AES), which sought perceptions of students about their academic environment developed and validated by the researchers, was used for data collection. Data collected were analysed using exploratory factor analysis technique and Cronbach alpha method. The Kaiser's rule (eigenvalue $\geq 1$ ) and scree plot were adopted in extraction of five factors as underlying structure of the instrument. The factors were labeled respect for students, academic guidance to students, commitment to academic work, relationship with lecturers and freedom of learning, based on the description of items that loaded on them. The index of logical validity of 0.90 and the reliability coefficient of 0.91 was also established for the instrument. It was concluded that factor analysis and reliability results provided clear evidence for factorial validity and reliability of the instrument. It was recommended, based on the findings, that the instrument should be used for exploring students' perceptions of personal and social academic environment variables and as a valid diagnostic tool for providing guidance and counseling support to students.
\end{abstract}

Keywords: Factorial validation, Academic environment scale

\section{Introduction}

The importance of conducive academic environment to sound teaching and learning cannot be over emphasized. The term Academic environment is used interchangeably with learning/school environment in some quarters. Academic environment therefore refers to the totality of the settings in which teaching and learning takes place. It can also be viewed as the atmosphere in which one attempts to learn, which can enhance or inhibit learning (Psychology Dictionary, 2014). According to Divaris, Barlow and Chendea (2008), a higher education environment, by definition, should foster both professional and personal development. It should offer a unique opportunity to cultivate values such as cooperation, volunteerism, service, among others, to those in need and more. They are also of the view that an ideal educational environment should enable students to acquire the necessary theoretical and interpersonal competencies and expose them to experiences equivalent to the environment in which they are likely to be after graduation. In support of this view, UNESCO (2002) stated that safe and orderly class room environment (instructional space) and school facilities (accessories) were significantly related to students' academic performance in school. It further asserts that a comfortable and caring environment among other treatments help to contribute to students' academic performance. Thus, academic environment comprises both the physical and psychosocial components.

The physical components include the classroom, class size, library facilities, the laboratories, lighting, temperature and the location of the school. Psychosocial components, on the other hand comprises the interactions that exit between the students and the lecturers, interaction between the students and the physical surrounding or components of the school system, as well as their emotion and attitude to academic work.

Research Methods and Statistics are core courses offered by all students in the Faculty of Education of 
Universities in Nigeria. The benefits of exposure of education undergraduates to theory and practice of research methods have been stressed. The benefits include motivating education undergraduates to become independent thinkers, preparing them for postgraduate programmes, providing them opportunities for showcasing their work (Anderson, Larsen, Bjerregaard \& Madson, 2003; Tan, 2007) and shaping students' attitudes, learning and achievement in the field of research as observed by Lombard and Kloppers (2015). The courses are taught in Faculties of Education in Nigeria to equip the students with knowledge and skills in different designs and approaches that could be utilized in conducting educational research and writing research reports in partial fulfilment for the award of bachelor's degree in their various fields of study. The overall goal of teaching and learning of these courses is to develop in the learner competencies required for finding solutions to problems facing the education system in the country.

However, despite the importance of these courses to the professional development of teachers in training as well as the attainment of the overall goals of university education of fostering the spirit of inquiry and the advancement of knowledge, students still perform poorly. Different factors such as student teachers' negative attitudes to research methods courses (Schutze, Droggozz, White \& Distefano, 1998; Macheski, Buhrmann, Lowrey \& Bush, 2008) that is often caused by frustration and difficulty in understanding research components and concepts (Tylor \& Muncer, 2000; Lodico, Spaulding \& Voegtle, 2004). Other factors are high anxiety levels among students (Papanastasious \& Zembylas, 2008) and broad nature of the courses as perceived by students. Jiao, Collins and Onwuegbuzie (2013) also attributed poor performance of students in the courses to diverse nature of students' population, poor mathematical background, insufficient training, low self-efficacy towards research skills, research anxiety, and poor reading ability, among other factors. Thus, the consistent poor performance of undergraduate education students in Research Methods and Statistics prompted the researchers to give attention to research methods for education students at the undergraduate level through development and validation of an instrument that can be used for exploring environment variables that may enhance or inhibit performance in the courses.

Literature review reveals that there are different perceptions of influence of academic environment on students' performance among authors. Okwilagwe (2004) developed and validated an academic environment scale which was used to measure the quality and efficiency of learning environment from the Nigerians students' perception. Her study reveals that there also exit low level of commitment to academic work by students and lecturers, poor academic relationship, lack of respect and personal attention to students, little or no academic guidance in our tertiary institutions. In support of this, Orlu (2010) and Ali (2013) stated that poor interaction/relationship between teachers and students is another environment variable which affects students' performance in tertiary institutions.

Furthermore, Uzoka and Fabiyi (2007) are of the view that academic environment in Nigerian Universities are deficient. They observe that there are inadequate classrooms to comfortably accommodate admitted students, the classes available are in poor state, laboratories lack necessary equipment to function and library materials are obsolete in many universities in the country. They also noted that adequate funds are not provided to pursue research activities which are the focal point of university education. In the same vein, Nwogu (2012) stated that academic/learning freedom in Nigerian tertiary institutions is faced with a lot of hurdles. He reiterated that both students and lecturers do not enjoy full liberty to inquire, carry out critical thinking and publish research findings. Also, Kenny (2014) stated that there is little or no academic guidance for many students in Nigerian tertiary education. He noted that often, guidance services are thin on the ground, with students not having access to the range of services they require to make informed educational decision. Thus, the paucity of these services affect their academic performance and require that emphasis be laid on exploring of psychosocial aspect of the school environment, where the education undergraduates learn research methods and statistics courses to determine whether or not it has influence on performance. Nonetheless, the paucity of valid and reliable academic environment scales for assessing quality of psychosocial aspect of learning environment in Nigeria necessitates this study.

The theory that provided basis for the explanation of the influence of the academic environment on the learning process and performance of students is Ecological Systems Theory developed by Urie Bronfenbrenner in 1977. The theory examined purely physical elements of school environment to more complex models of psychosocial relations between students in the classrooms as well as between the teacher and students. The theory assumes that the school environment consists of four environment systems: Microsystem, Mesosystem, Exosystem and Macrosystem. In his model, the centre is the student surrounded by different systems. The microsystems are the immediate settings in which the child lives, such as school. Mesosystems represent the relationships between different microsystems and the people in the microsystems. The exosystem includes the social organizations, agencies, and services which the child does not have direct interaction with. Macrosystems are attitudes and ideologies of the culture in which the child lives. In Bronfenbrenner's theory, there is one more layer, which is not cited in every resource, called the chronosystem, which represents "the patterning of environmental events and transitions over the life course, as well as socio-historical 
circumstances" (Santrock, 2001, p. 47).The theory further stated that there is a strong, positive relationship between students' level of commitment to their studies and their perceptions of the classroom environment (Miller and Cunningham, 2011). Thus, the theory lays emphasis on the importance of teachers, school and the larger sociocultural environment on the developmental learning process of the learner and associates academic environment variables with numerous positive and negative students' outcomes. This relation between academic environment and performance of students requires that valid and reliable instruments should be developed and used for assessing environment variables that influence education undergraduate students' performance. Thus, the purpose of the study was to develop and validate a scale that should be used as a diagnostic tool for improving psychosocial academic learning environment variables in order to enhance performance of undergraduate education students in the University. In order to achieve this purpose, the following research questions were raised:

1. What is the factor structure of the scale?

2. What are the dimensions of the scale?

3. What are the reliability coefficients of internal consistencies of Academic Environment Scale (AES) and its subscales?

\section{Research Methods}

The study was an instrumentation research that dealt with the development and factorial validation of an academic environment scale for undergraduate education students of a Nigerian University. Instrumentation research design provides the basis for the development and use of research instrument in the research process and this helps in data collection and provides basis for reaching meaningful conclusion in educational research. The population of the study comprised 790 undergraduate education students from different departments in a Faculty of Education University in a Nigerian university in 2013/2014 academic session. Data were collected from a sample of 310 undergraduate education students from different programmes in the Faculty.

Stratified random sampling technique was used for the selection of sample from the population. The choice of this sampling technique is to ensure equal and independent probabilities of selecting elements of the population from the different programmes of the Faculty to be included in the sample. The items of the instrument were developed by the researchers after extensive review of relevant literature. However, relevant items of the Academic Environment Scale (AES) in the areas of commitment to academic work by students/ lecturers, relationship with lecturers, freedom in students learning, academic guidance of students, personal attention to students and respect for students were adapted from the works of Okwilagwe (2004), Gaff, Crombag and Chang, (1976) and Ramsden (1979).

Content was established through subjecting the instrument to the scrutiny of three experts in the field of Test and Measurement, Educational Psychology and Social Studies Education to examine the extent to which the items on the instruments measured the construct of the dimensions of the scale, as well as if the items adequately covered the relevant aspects of the construct so measured. The index of logical validity for the scale was 0.90 . Construct validity was also established through factor analysis to determine the extent to which academic performance of students can be interpreted in terms of certain psychological constructs such as commitment, relationship, freedom, guidance, respect and attention used in the study.

The data collected were analyzed using the Statistical Package for Social Science (SPSS) software. Responses from the instruments were coded and analysed. Factor analysis was used to determine the factor structure of the instrument, while reliability analysis was run to determine the Cronbach alpha coefficient of internal consistency reliability the scale and its subscales. To establish the factor structure of the Academic Environment Scale for undergraduate education students Exploratory Factor Analysis (EFA) was carried out. EFA was used to explore possible underlying factor structure of a set of observed variables without imposing preconceived structure on the outcome (Williams, Brown, and Onsman, 2010).

Data screening was done with the use of Pearson Correlate Coefficient Matrix with the aim of determining the pattern of relationship among the items of the instrument. The determinant for correlation matrix for the Scale was 6.87E$011(0.000687)$ which is greater than the necessary value of 0.00001 . Therefore, multicollinearity was not considered to be a problem for the data. Since all the items of the scale correlate fairly well and none of the correlation coefficients are particularly large, no factor was eliminated at this stage. Furthermore, Kaiser-Meyer-Olkin (KMO) measure of sampling adequacy and Bartlett's test of sphericity were used to assess the suitability of the data for factor analysis. The KMO index for the scale was 0.81 indicating that the correlation matrix was factorable. The Bartlett's test for this scale is highly significant ( $p<0.001)$, and therefore factor analysis is appropriate (Field, 2005). 


\section{Result}

\subsection{Factor Structure of the Academic Environment Scale}

Principal Components Analysis (PCA) was conducted to confirm the appropriate number of factors to be extracted. Thompson and Daniel (1996) recommended the use of multiple criteria for factor extraction. They include Kaiser's criterial (eigenvalue $>1$ rule, Kaiser, 1960), Scree test (Cattell, 1966), cumulative percentage variance extracted (Harn, 1965) and 50-60\% explained variance threshold for stopping extraction of factors (Hair, Tathan and Black, 1995). The PCA was run using 43 items and 12 factors were extracted accounting for $68.41 \%$ variance. This simply means that the 12 factors that loaded with eigenvalue greater than 1 are responsible for $68.41 \%$ of variations in students' response in terms of their perceptions of the academic environment. Factor 1 contributed the highest percentage variance of $23.41 \%$ with eigenvalue of 10.01 , while factor 12 contributed the least percentage variance of $2.34 \%$ with eigenvalue of 1.01 . The summary of this is presented in Table 1.

Table 1: Percentage Cumulative Variance for the scale on Research Statistics

\begin{tabular}{cccc}
\hline Factors & Eigenvalue & \% of variance & Cumulative \% \\
\hline 1. & 10.07 & 23.41 & 23.41 \\
2. & 3.65 & 8.48 & 31.89 \\
3. & 2.75 & 6.40 & 38.29 \\
4. & 2.12 & 4.92 & 43.22 \\
5. & 1.80 & 4.18 & 47.40 \\
6. & 1.66 & 3.85 & 51.25 \\
7. & 1.45 & 3.37 & 54.62 \\
8. & 1.38 & 3.22 & 57.84 \\
9. & 1.27 & 2.94 & 60.78 \\
10. & 1.20 & 2.79 & 63.57 \\
11. & 1.08 & 2.50 & 66.07 \\
12. & 1.01 & 2.34 & 68.41 \\
\hline
\end{tabular}

The elbowing point in the scree plot occurred between $5^{\text {th }}$ and $6^{\text {th }}$ components, with $47.40 \%$ of the variance accounted for by the first-five components (all with eigenvalues $>1.0$ ). The scree plot is shown in Figure 1. The researcher chose the fifth factor based on Kaiser (1974) recommendation.

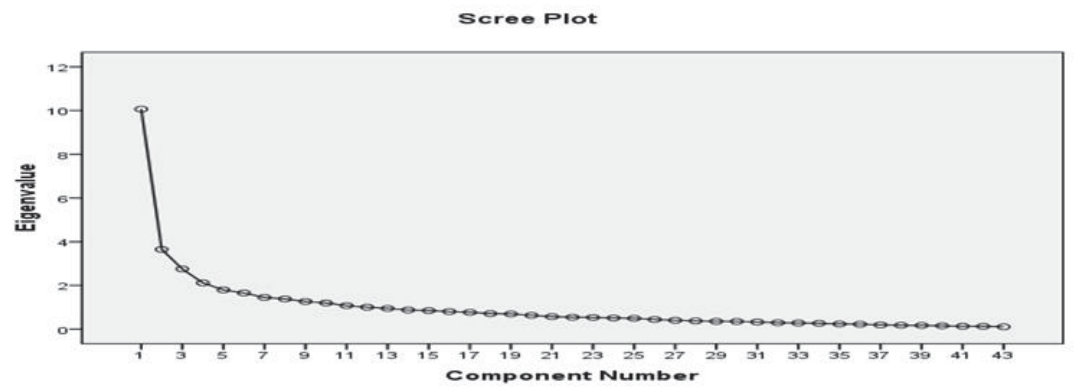

Figure 1: Scree plot for Academic Environment Scale (AES) for Research Statistics

Therefore, since the items were uncorrelated, Orthogonal Varimax rotation method was employed. The result in the Table 2 shows that the items loadings less than 0.40 were excluded. The analysis yielded a five-factor solution with a simple structure (factor loadings $\geq 0.40$ ). Thus, the items that do not load on any factor and those that loaded on several factors $(1,2,3,4,5,6,14,18,21,22,23,32,36,37$ and 38) were considered complex and discarded. The items that loaded on a factor were carefully studied and label appropriately based on the underlying tune of the items. Table 2 shows items that loaded on each factor. 
Table 2: Rotated Component Matrix for 28 items

\begin{tabular}{|c|c|c|c|c|c|}
\hline COMPONENTS & 1 & 2 & 3 & 4 & 5 \\
\hline Q42: Needs & 0.832 & & & & \\
\hline Q41: Feelings & 0.821 & & & & \\
\hline Q43: Recognition & 0.774 & & & & \\
\hline Q39: Adequate time & 0.746 & & & & \\
\hline Q40: Commitment & 0.448 & & & & \\
\hline Q30: Feedback & & 0.759 & & & \\
\hline Q35: Attention & & 0.703 & & & \\
\hline Q29: Proper guidance & & 0.671 & & & \\
\hline Q31: Supervision & & 0.659 & & & \\
\hline Q28: Discussion & & 0.649 & & & \\
\hline Q34: Intellectual development & & 0.410 & & & \\
\hline Q12: Adequate preparation & & & 0.799 & & \\
\hline Q10: Punctuality & & & 0.712 & & \\
\hline Q9: Innovation & & & 0.675 & & \\
\hline Q11: Commitment & & & 0.659 & & \\
\hline Q13: Steadfastness & & & 0.624 & & \\
\hline Q8: Dedication & & & 0.558 & & \\
\hline Q7: performance & & & 0.430 & & \\
\hline Q15: Interest & & & & 0.712 & \\
\hline Q16: Needs & & & & 0.680 & \\
\hline Q17: Aspiration & & & & 0.596 & \\
\hline Q20: Academic support & & & & 0.554 & \\
\hline Q19: Emotional support & & & & 0.542 & \\
\hline Q33: Approachability & & & & 0.473 & \\
\hline Q26: Skills of analysis & & & & & 0.771 \\
\hline Q25: Advancement in knowledg & & & & & 0.747 \\
\hline Q27: Critical inquiry & & & & & 0.738 \\
\hline Q24: Liberty & & & & & 0.687 \\
\hline Number of items & 5 & 6 & 7 & 6 & 4 \\
\hline
\end{tabular}

\subsection{Dimensions of the Academic Environment Scale (AES)}

Five items $(39,40,41,42$ and 43$)$ loaded on Factor 1 . The items which loaded on this factor relate to respect given to students by lecturers. Thus, this factor was labeled "Respect for students by lecturers". Six items $(28,29,30,31,34$ and 35) loaded on the second factor. These items reported guidance given to students. This factor was named "Academic guidance to students". The seven items $(7,8,9,10,11,12$ and 13) that loaded on factor three reported students' and lecturers' commitment to the teaching and learning. The factor was labeled "commitment to academic work". The six items $(15,16,17,19,20$ and 33) that loaded on factor four reported the level of relationship between lecturers and students. This factor was labeled "Relationship with lecturers". Four items (24, 25, 26 and 27) loaded on the fifth factor. These items reported students' freedom in learning. Thus, this factor was named "freedom in students' learning". The dimensions of the Academic Environment Scale is presented in Table 3, which gives description of the components of the scale. The Table also shows the list of items that loaded on each factor.

Table 3: Dimension of Academic Environment Scale for Undergraduate Education Students

\begin{tabular}{|c|c|c|c|c|}
\hline $\mathrm{S} / \mathrm{n}$ & AES Subscale & No. of items & Description & Items \\
\hline 1 & Respect for students & 5 & $\begin{array}{l}\text { Recognizing and respecting students } \\
\text { uniqueness, needs and feelings, } \\
\text { showing commitment to teaching as } \\
\text { well as allocating adequate time to } \\
\text { students to solve their problems }\end{array}$ & $39,40,41,42,43$ \\
\hline 2. & $\begin{array}{l}\text { Academic Guidance to } \\
\text { students }\end{array}$ & 6 & $\begin{array}{l}\text { Personal attention and guidance given } \\
\text { to students by way of supervision, } \\
\text { feedback and listening to their view }\end{array}$ & $28,29,30,31,34,35$ \\
\hline 3. & $\begin{array}{l}\text { Commitment to academic } \\
\text { work }\end{array}$ & 7 & $\begin{array}{l}\text { Dedication to duty by lecturers } \\
\text { expressed through innovative way of } \\
\text { teaching and commitment, adequate } \\
\text { preparation, punctuality and } \\
\text { steadfastness }\end{array}$ & $7,8,9,10,11,12,13,14$ \\
\hline 4. & Relationship with students & 6 & $\begin{array}{l}\text { Responsiveness to students needs } \\
\text { expressed through being sensitive to } \\
\text { their needs and aspirations, support } \\
\text { through encouragement and being } \\
\text { approachable }\end{array}$ & $15,16,17,19,20,33$ \\
\hline 5. & Freedom in students leaming & 4 & $\begin{array}{l}\text { Freedom of leaming expressed by } \\
\text { allowing students to source for } \\
\text { additional leaming materials, develop } \\
\text { skills of critical inquiry and express } \\
\text { interest }\end{array}$ & $24,25,26,27$ \\
\hline & Total & 28 & & \\
\hline
\end{tabular}




\subsection{Reliability Coefficients of Internal Consistencies of AES and its Sub-Scales}

The reliability of internal consistencies of the AES and its sub-scales were determined using Cronbach coefficient alpha. The coefficients of internal consistencies are presented in Table 4. The reliability coefficient obtained for the instrument was 0.91 and the coefficients of its sub-scales ranged from 0.78 to 0.85 , which were judged to be high and adequate (Fraenkel and Wallen, 1993). The estimate further shows that the items on the instruments were quite homogeneous and reliable.

Table 4: Internal Consistency Reliability Coefficients for Academic Environment scale (AES) and Sub-Scales

\begin{tabular}{llcc}
\hline & AES Sub Scales & Number of items & Intemal Consistency $(\alpha)$ \\
\hline 1. & Respect for students by lecturers & 5 & \\
2. & Academic guidance to students & 6 & 0.85 \\
3. & Commitment to academic work & 7 & 0.85 \\
4. & Relationship with lecturers & 6 & 0.81 \\
5. & Freedom in students' leaming & 4 & 0.83 \\
& & & 0.78 \\
& & & \\
& & & \\
\end{tabular}

\section{Discussion}

The finding relating to research question one was that 12 factors that accounted for $68.41 \%$ of the total variance in perceptions of academic environment factors for Research Statistics was extracted. However, the factors that were found to best approximate simple structure in terms of achieving easy interpretation were five and they accounted for $47.40 \%$ of the total variance in the perceptions of academic environment factors for Education students. This implies that academic environment variables are not the only factors that affect education undergraduate students' performance in research methods and statistics. The finding is corroborated by the findings that students' perceptions of the research concepts as difficult (Tylor \& Muncer, 2000; Lodico, Spaulding \& Voegtle, 2004), their negative attitudes to research methods courses (Schutze, Droggozz, White \& Distefano, 1998; Macheski, Buhrmann, Lowrey \& Bush, 2008) and high level of anxiety lower performance in the courses (Papanastasious \& Zembylas, 2008). Other factors identified in literature include diverse nature of students' population, poor mathematical background, insufficient training, low self-efficacy towards research skills and poor reading ability (Jiao, Collins \& Onwuegbuzie, 2013).

The data collected passed the Kaiser-Meyer-Olkin test of sample adequacy and Bartlett's sphericity test of suitability of data for factor analysis this lend credence to the factor structures of the scales. Furthermore, the resulting factor structure of the Academic Environment Scale (AES) for Research Statistics is also corroborated by the findings of Okwilagwe (2004), Gaff, et al (1976) and Ramsden (1979), except for some dimensions not represented in the scale. The slight difference between the dimensions of the scale in the present study and those of earlier studies may be attributed to cultural differences. In the Gaff et al. study, the original instrument developed from American background was modified to suit the European environment. After modification it consisted of 10 sub-scales. However, Ramsden (1979) reported that after analyzing the instrument for use in British University, eight significant factors were isolated. The development of the Academic Environment Scale (AES) for Research Statistics has contributed to the understanding of the academic learning environment of education undergraduates in the university under study.

The findings from research question two presented in Tables 3 shows that five factors were extracted from the scale and that five items loaded on factor one and was labeled respect for students, six items loaded on factor two and was labeled academic guidance to students, seven items loaded on factor three and was labeled commitment to academic work, six items loaded on factor four and was labeled relationship with lecturers while four items loaded on factors five and was labeled on freedom in students' learning. In all, twenty eight items loaded on five factors after factor analysis. The five dimensions of the Academic Environment Scale are respect for students, academic guidance to students, commitment to academic work, relationship with lecturers and freedom in students' learning. These findings are corroborated by Okwilagwe (2004) findings in that similar factors were extracted in her work after factor analysis. Therefore, this signifies that these academic environment factors are important in enhancing teaching and learning research methods and statistics courses in the university and beyond, hence the need create the enabling academic environment for enhancing students' performance in research methods and statistics courses.

Findings from reliability analysis presented in Table 4 shows that the Academic Environment Scale and its sub- 
scales are reliable and adequate as judged Fraenkel and Wallen (1993). The estimates further show that the items of the instruments are quite homogeneous and can be used to measure the perceptions of Education students' academic environment overtime for appropriate action to be taken for quality assurance.

Since the Academic Environment Scale (AES) for Undergraduate Education Students is a valid and reliable instrument, it was recommended for use by any researcher who intends to collect data on students' perception of their academic environment factors within the University and beyond. It can also be used as a valid and reliable diagnostic tool to identify the cause of academic failure attributable to academic learning environment in research methods and statistics courses and for improving psychosocial academic learning environment variables in order to enhance performance of undergraduate education students in the courses.

\section{Conclusion}

The purpose of this study was to develop and validate an academic environment scale for undergraduate education students in the Faculty of Education of a Nigerian University. The study was motivated by dearth of valid and reliable academic environment scales and persistent poor performance of students in Research Methods and Statistics over the years. Principal Components Analysis (PCA) was conducted to confirm the number of factors to be extracted. Five factors were extracted for the instrument and each of the factors was labeled based on the description of items that loaded on them. The index of logical validity was 0.90 while the reliability coefficient of the instrument was 0.91 . Based on the findings of the study, it was concluded that the Academic Environment Scale (AES) for undergraduate education students is a valid and reliable academic environment scale, which can be used to collect data on students' perceptions about their psychosocial academic environment variables. The data collected would be useful to lecturers and students in making necessary adjustments in their behavior and practices in order to improve students' performance in the research methods and statistics courses.

\section{References}

Academic Environment (2014). In Psychology Dictionary. [Online] Available: www.http://psychologydictionary/academicenvironment (June 12, 2014)

Ali, H.O. (2013). Factors affecting students' academic performance in mathematical sciences department in tertiary institutions in Nigeria. US-China Education Review, 3 (12), 905-913.

Cattell, R.B. (1966). The Scree test for the number of factors. Multivariate Behavioral Research, 1 (2), $247-76$.

Divaris, K., Barlow, P., \& Chendea, S. (2008). The academic environment: The students' perspective. European Journal of Dental Education, 12 (1) 120-130.

Field, A.P. (2005). Factor analysis using SPSS. [Online] Available: http://www.sagepub.co.uk/field/multiplechoice.html (March 5, 2015)

Fraenkel, J.R., \& Wallen, N.E. (1993). How to design and evaluate research (2nd ed.). New York.

Gaff, J.G., Crombag, H.F., \& Chang, T.M. (1976). Environment for learning in a Dutch University. Journal of Higher Education, 5, 285299.

Hair, J., Anderson, R.E., Tathan, R.L., \& Black, W.C. (1995). Multivariate data analysis (4th ed.). New Jersey: Prentice Hall Inc.

Harn, J.L. (1965). A rationale and test for the number of factors in factor analysis. Psychometrical, 30 (2), 179-85.

Jiao, Q., Collins, K., \& Onwuegbuzie, A. (2013). Research methodology courses: the role of study coping and examination-taking coping strategies. [Online] Available: http://www.collegequarterly.ca/2013-vol16-num02-spring/jiao.html (September 11,2014)

Kaiser, H.F. (1974). The application of electric computers to factor analysis. Educational and Psychological Measurement, 1 (2), $141-51$.

Kenny, F. (2014). Career education and guidance in schools. [Online] Available: http://fitzjkenny.hubpages.com/hub /careerdecisionmissinglink (October 29, 2014)

Lodicao, M.G., Spaulding, D., \& Voegtle, K. H. (2004). Promising practices in the teaching of educational research. Paper presented at the Annual Meeting of the American Educational Research Association, April, San Diiego, CA.

Lombard, B.J.J., \& Kloppers, M. (2015).Undergraduate student teachers' views and experiences of a compulsory course in research methods. South African Journal of Education, 35(1), [Online] Available: http://www.sajournalofeducation.co.za (May 5, 2016)

Miller, A., \& Cunningham, K. (2011). Classroom environment. [Online] Available http://www.education.com/reference/article/classroomenvironment/ (July 15, 2014)

Nwogu, G. (2012). Democracy and academic freedom in Nigeria. A philosophical perspective, developing country Studies, 5(2), 1-6.

Okwilagwe, E.A. (2004). Developing and validating academic environmental scale for Nigerian students. In J.O. Obemeata and E. A. Okwilagwe (Eds.). A Handbook on evaluation research, pp. 1-11.

Onwuegbuzie, A. J., \& Wilson, V. A. (2003). Statistics anxiety: Nature, etiology, antecedents, effects and treatments- a comprehensive review of the literature. Teaching in Higher Education, 8(2), 195-209. Doi: 10.1080/1356251032000052447

Orlu, C. (2013). Environmental influence on academic performance of secondary school students in Port Harcourt local government area of River state. Journal of Economics and Sustainable Development, 4 (12), 34-38. [Online] Available www.iiste.org (October 27, 
2014)

Papanastasiou, E. C., \& Zembylas, M. (2008). Anxiety in undergraduate research methods courses: Its nature and applications. International Journal of Research and Method in Education, 3(4), 155-167.

Ramsden, P. (1979). Student learning and perceptions of the academic environment. Journal of Higher Education, 8, 411-427.

Santrock, J.W. (2001). Child development. Boston: McGraw-Hill.

Schindler, V. P. (2011). Using service-learning to teach mental health and research skills. Occupational Therapy in Health Care, 25, 5464.

Schuz, P. A., Drogosz, L. M., White, V. E., \& Distefano, C. (1998). Prior knowledge, attitude and strategy use in an introduction to statistics course. Learning and Individual Differences, 10(4), 291-308. Doi:10.1016/S1041-6080(99)80124-1

Tan, E. B. (2007). Research experiences of undergraduate students and teacher educators. International Journal of Teaching and Learning in Higher Education, 19(3), 205-215.

Taylor, S. \& Muncer, S. (2000). Redressing the power and effect of significance: A new approach to an old problem: teaching statistics to nursing students. Nurse Education Today, 20(5), 358-364.

Thompson, B. Daniel, L.G. (1996). Factor analytic evidence for the construct validity of scars: A histotical overview and guideline. Educational and Psychological Measurement, 56 (2), 197-208.

UNESCO (2002). The state of education in Nigeria, October. Abuja: Nigeria.

Uzoka, N., \& Fabiyi, A. (2007). State of Physical Facilities in Nigerian Universities: Implication for repositioning tertiary institutions for global competition. Towards Quality in African Higher Education, 180- 187.

Williams, B., Brown, T., \& Onsman, A. (2010). Exploratory factor analysis: A five step guide for novies, Australian Journal of Paramedicine, 8(3), 324-325. [Online] Available: http://ro.ecu.edu.au/jephc/uds/iss3/1 (March 6, 2015) 